\title{
De-Mystifying Inventive Thinking: A Survey With Pedagogic Implications
}

\author{
Andre Clark, University of Glamorgan, Wales
}

\begin{abstract}
Students on an enterprise course running in a number of colleges in the UK in which invention and innovation formed part of the curriculum were asked to complete a questionnaire immediately upon having an inventive thought in an attempt to establish the thinking processes involved. Results from those who had ideas that subsequently proved to be genuinely inventive are presented in this paper. The results show that such thinking is most frequently categorised by the thinker in terms that suggest it is similar to other everyday modes of thought, rather than anything more mysterious. The implication of this research is that accessing the kind of creativity required to begin students inventing is not as problematic as has previously been assumed, although it can be made so by approaches that fail to take account of the need for problem construction and the need to overcome the inertia created by the extent to which invention has been mythologized in the minds of both students and teachers.
\end{abstract}

Keywords: Teaching Invention; Inventive Thinking; Psychology of Creativity

\section{BACKGROUND}

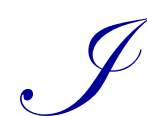

n 1945, Vannevar Bush published a paper that outlined the principles of hypertext. By the 1980's, hypertext had spawned such a plethora of modes of communication between computers that users were crying out for standardisation. One such call came from Tim Berners-Lee, and the first node of a standardised system that we now know as the Internet was established in his office using the NCSA's hypertext based Mosaic system. This story, brief as it is, highlights a common feature of great inventions - rapid assimilation after diffusion, but gradual accretion prior to it. However, if we ask who invented the Internet, we tend to get the answer 'Tim Berners-Lee'. This reflects a tendency that people seem to share to cut a long story short by personifying a great idea in a great person; to ascribe it to individual genius. It may seem very reasonable to assume that something exceptional should be the product of someone exceptional, or at least of some exceptional thoughts; but the results presented in this paper challenge that assumption. This is not to say that the 'great man' view of invention has never been challenged before. Authors, such as Bijker (1987) and Hughes (1983), challenge it by showing how many of today's industries were built on dispersed inventive elements while others, such as Scranton (1977), Allen (1983), and Meyer (2003), highlight the importance of collaboration and interaction in bringing such elements together. The challenge made here is, however, rather different; the issue being less about whether inventions rely on the efforts of exceptional people - or not - and more about whether the thinking employed is, itself, exceptional.

\section{INVENTIVE THINKING, PSYCHOLOGY, AND NEUROSCIENCE}

In psychology literature, there is little on inventive thinking per se, but there is a considerable amount of research into creativity; and since - as Morgan (1953) points out - definitions of creativity share a common emphasis on novelty and originality with invention, this can be assumed to encompass the standard view of what inventive thinking entails. The literature on creative thinking should, however, be viewed in the context of the failure of psychologists to identify the underlying processes involved in thinking, in general. As Stanovich and West (2000) show, the development of a theory that, by encompassing the most significant findings to date, could lay any claim to generality (Hendry and Richard, 1989) is proving elusive and what we have instead is a proliferation of dichotomies between different types of thinking - associative versus rule-based, experiential versus rational, implicit 
versus explicit, and so on and so forth. In addition, although authors, such as Stanovich and West (2000), have done their best to tidy things up, it seems inevitable that dichotomous approaches - being primarily descriptive - will continue to proliferate in the absence of anything more profound. The dichotomy most often used to distinguish creative from other forms of thought emphasises its supposedly intuitive, non-linear, lateral, divergent and unpredictable nature. This specific bifurcation was given a huge boost in the 1960's by brain research of Roger Sperry and others who found certain polarities between left and right hemispheres. One such being is that information processing by the right hemisphere appeared to exhibit gaps that were less apparent on the left, possibly relating to the visual processing dominance on the right and verbal processing dominance on the left. In the popular media, this translated into the view that there was one creative hemisphere and one analytical one, with the creativity resting on something that had not been explained since the gaps indicated thoughts that emerge with no immediate precedence or, as it is often phrased, 'like bolts from the blue' (sky). Interpreting these gaps as intuitive leaps, rather than as limitations of the research, confirmed the view that creativity is intrinsically mysterious. Even in the scientific community, absence of evidence tended to be taken as evidence of absence in concluding that the inner workings of the brain showed creativity to be something extraordinary.

Today we live with this legacy, one result of which is that radically different pedagogic approaches are often taken to bring out the creative side of students. One of the best known proponents of the validity of this difference is Edward de Bono, who argues that breaking free of ordinary thinking is a prerequisite of inventive thinking. Indeed, the argument that ordinary modes of thought have to be transcended to liberate the creative ones is forcibly expressed in many self-help books, as Koestler (1975) puts it - "The creative act...presupposes a relaxing of the controls and a regression to modes of ideation which are indifferent to the rules of verbal logic, unperturbed by contradiction, untouched by the dogmas and taboos of so-called common sense". (p.165) Of course, part of this distancing is motivated, in some at least, by a desire to sell self-help books and the like (Hines, 1987). However, it cannot be dismissed easily since this separation is ubiquitous in the academic literature too, (see, for example, Finke et al., 1992). Indeed, although Heilman et al. (2003) admit that there are no firm conclusions from this research as yet, they seem to be nonetheless content to conclude that creativity entails something out of the ordinary - "creative innovation might require the coactivation and communication between regions of the brain that ordinarily are not strongly connected" (ibid., p.369). As if that were not bad enough, although some neuroscientists recognise that "much more work is needed in order to establish reliable and valid measures of creative thinking, in particular measures of novelty or originality of creative insights" (Fink et al., 2007, p.68), the fact that we may not have identified what it is has done nothing to stop competing teams of neuroscientists from trying to explain it. Moreover, it is possible to detect an element of assumed causality in discussions of creativity that is absent in other aspects of brain research. For example, a recent unpublished study by Geraint Rees and his colleagues at University CollegeLondon, showing a correlation between Tory political views and physical thickening of the Amygdala, led to a widespread discussion of the opposing possibilities in the media (Churcher, 2010, for example) - in short, that it was either caused by certain propensities of thought (since brain structure is not fixed) or was the cause of them. However, nowhere, even in what we might describe as the most popular of the popular press, was it seriously suggested that voting Tory could be wholly reduced to this thickening, particularly when what that party represents has changed so much in recent years. In contrast, discussions of creativity, which the story of modern art and literature teaches us, is equally changeable and certainly more open to interpretation than support for a political party is often crudely reduced in this way, and not just in the popular press.

The fact that people use one part of their brains when solving well-defined problems and another when engaging in more creative thinking (Fink et al., 2008) is not the issue. Rather, it is the interpretation of this result as it is apparent that those conducting such tests tend to assume that because the results of creative thinking are often exceptional, then creative thinking itself must be exceptional. Even those psychologists, who point to the need for a more rounded and holistic approach to the issue than brain-mapping provides, are often motivated by its rarity and the need, therefore, to get more of it occurring (Sternberg, 1985; Sternberg and Lubart, 1995). However, its rarity as a mode of thought is not established by studies in which it may or may not be correctly identified and in which we cannot find it anyway, 'coactivated' or not. So, we are forced back on the rarity of great art and major inventions as indicators of the rarity of the kinds of thoughts that give rise to them. The frequency with which we use our creative imaginations in our everyday lives, not just in obvious ways like daydreaming, but in imagining different scenarios for all manner of daily decisions, remains unknown, however, and the possibility that creative thinking is unexceptional remains a distinct possibility. In addition, recent research by Meneely and Portillo (2005) suggests 
that creativity requires not adherence to a particular cognitive approach, but the ability to adopt and adapt different styles, which points to complexity rather than something amenable to reduction. A complexity which is further complicated by social interaction, since as Kurtzberg (2000) found, adding apparently 'non-creative' participants into a group of apparently 'creative' individuals can lead to greater creativity - not less.

Very little of the psychological research referred to above relates to invention per se, although some specific forms of creativity have been studied using brain scanning techniques - for example, by Geake and Hansen (2005) and Chavez-Eakle et al., (2007) - which could be used to look at some forms of inventive activity. Duch (2007), for example, suggests that we may be able to scan people in the act of making very simple 'inventions', such as the forming of novel words from suggested word pairings. This is not what we would generally mean by the term invention, however, and is a long way short of what the students involved in this study have achieved. In the future, we might expect that many of the activities undertaken by the students in this study (as described in Clark, 2009) could be done while some form of scan is undertaken when brain-scanning technology shrinks in terms of both cost and bulk. Until this is done, we have to conclude that it is only an assertion that inventive thinking and other everyday modes of thought are radically different. That this assertion is, at least, greatly exaggerated is supported by historical studies of some major inventions undertaken by Weisberg (1993) which showed that many inventive 'bolts from the blue' evolve and accumulate rather more slowly than the analogy to lightning would suggest. Indeed, in reading many of the cases he refers to, it is hard not to be struck by the similarity between inventive thinking and the thinking routinely employed by scientists in generating hypotheses and conceiving various alternatives in the lab - or, indeed, much difference between this and the degree of imagination students employ in generating hypotheses and conceiving alternatives about which nightclub to go to at the weekend. Of course, many cases of invention are, in fact, scientists working in laboratories and often the two get mixed up; and in some cases, inventors are happy to encourage the mixing when it suits them. At Edison's invention factories, for example, every invention was attributed to Edison's final twist on ideas that his scientists may have been working on for years, even if that twist amounted to no more than the signing of his name. This is not to suggest that this is typical, but we might expect, at a bare minimum, that those so labelled are unlikely to be the first to challenge the 'great man' story of invention. The question addressed in this paper is not, however, whether a particular outcome is more to do with perspiration or inspiration, but what kind of thought processes are involved at the moment of greatest insight either way, which this kind of historical investigation cannot answer. Even when it is possible to ask those involved to reflect back upon their thinking, it is problematic since time will have elapsed; and in that time, any thought is bound to take on all kinds of different significances if it proves to be a great one. The solution used in this study is to ask those who have an idea to catalogue it against a list of thinking types commonly found in the literature immediately after having had the idea, regardless of the fact that at that stage its inventiveness is unconfirmed.

\section{THE EXPERIMENT}

This study relates to an experiment in teaching invention undertaken at the University of Glamorgan and its associated colleges in Wales (mostly) and England, entailing a range of activities aimed at encouraging students to invent, as outlined in Clark (2009). The number of participants in the experiment is large, but the number in this study is only 30 because the survey is based not on the number of participants or the number of ideas generated, but only on those ideas that have been patented or sent forward for formal examination by the patenting office (having passed both an in-house test of patentability and having been judged worthy of the financial backing that such progression requires). A problem with this approach is that since the number of patentable ideas is small relative to the number of participants, more than one cohort of students is covered and, as a result, the experimental conditions cannot be assumed to be identical in different years.

The questions in the survey, as shown in the Appendix, relate both to some general conditions and impressions, as well as a self-assessment of the thought process that led to the idea, using a classification of types of thought which had been previously discussed with the students. The form was filed voluntarily by the students whenever they felt that they had come up with a good idea in an attempt to capture their thoughts on their thinking as contemporaneously as possible. Since at the point of having the idea the student is unaware that they may not have been the first to think it, the questionnaire was designed to be short (one piece of A4 paper) and easy to complete in class or at home. The alternative would be to look at all ideas; but in this context, such a strategy is flawed since there is no way of knowing whether the respondent is genuinely unaware of it, even subconsciously. 


\section{GENERAL RESULTS}

Although the focus of this paper is modes of thought, other related issues were briefly investigated. One obvious question was whether the successful ideas came from people who felt creative, which seemed to be the case with $67 \%$ support for the first question. However, it is just as interesting to look at it the other way around and note that one-third of the people who were most successful at this creative task did not see themselves as creative, confirming one of the tenets of the original experiments that being a creative type was not a necessary prerequisite. Another issue is whether working in groups encourages invention, which is of particular interest here since different modes of thought may be engendered by interaction. Some authors claim to have quantified clear and significant gains to group work in generating ideas. Osborn (1957), for example, suggests that a group could generate twice as many ideas as the constituent individuals working independently, using his 'brainstorming' approach. This claim has, however, been criticised (Taylor et al., 1958, for an early example), and once we standardise for quality, the benefits of group work in this area have been observed to evaporate (Diehl and Stroebe, 1987). Nonetheless, since there is at least the possibility that group work might help, and given that the original idea of this work was to encourage invention, both individual and group approaches were employed and can now be compared. Indeed, since the test employed here is, in large part, standardised for quality, this research may be considered to have an advantage over previous studies. In doing this, every effort was made to make it a fair test by tackling issues that are seen to inhibit good group thinking. For example, the suggestion that members of groups may feel inhibited about revealing their most bizarre ideas (Lamm and Trommsdorff, 1973), of really letting go of their social inhibition in the group situation (Jablin and Seibold, 1978) led to an approach being adopted that encouraged outrageous ideas from the start. This cannot, of itself, eliminate the sideways glance or wry smile which may be all it takes to note disapproval in a small group setting, but it is likely to have helped create a mood in which inhibitions were reduced, although the effect of this is unclear as less than half supported the statement that 'coming up with strange ideas is a necessary part of the inventive process'. To what extent the success of group work can be attributed to how it was done is therefore still a moot point, despite the fact that the results presented here are very positive for group work with $87 \%$ of respondents agreeing or strongly agreeing with the statement that 'the group brought out my creativity'. Indeed, in the evaluation of the thought processes, 'An idea that someone else had in the group made me think of it' was the second most popular answer. This is not to say that the groups always gelled, of course, and regrettably, we cannot draw any conclusions about the relative proportion of ideas that result from group work given the dynamic nature of the class activities, although it is probably fair to say that more than half entailed some element of group interaction. In the questionnaire, there is also some support for the findings of a recent study by Baer et al. (2010) showing that competition encourages creativity, as $80 \%$ of the sample agreed or strongly agreed with the statement that they 'wanted to beat the others in this task'. Indeed, although collaboration and competition are often juxtaposed as opposite paths to greater productivity, in this case we see the importance of both simultaneously in generating successful new ideas, with significant overlaps between wanting to beat the others and recognition of the benefits of group work. Another significant issue was gender as most well-known inventors have been men. This could be due to the relatively inventive nature of their thinking, a notion supported by $70 \%$ of the students in this study who agreed that 'Men are the best at invention because men think differently'. Or it could be due to historical differences in the status and roles of the different sexes, which is supported by the fact that almost half (47\%) of the successful ideas in this study actually came from women. A final issue that was investigated was motivation, with this being tackled both by a direct question regarding the respondent's desire (or otherwise) to do well in the task and by an assessment of their disposition toward it by asking whether they had enjoyed it or not. Both of these questions elicited strong support (63\% and $70 \%$ strong agreement, respectively), indicating that success in this task was related to effort, application, and modes of thought that can be bent to the will rather than anything more mercurial.

\section{SPECIFIC RESULTS ON THOUGHT PROCESSES}

The most commonly cited category of thinking was Analogous Reasoning (47\%), which describes situations in which we transfer what we know in one area to another; although when applying it to novel situations, this is also referred to as transduction in the psychology literature. Examples of where inventors transfer an observation from one context to another include George de Mestral's invention of Velcro following his observation of the way burrs stuck to his dog's fur. More generally, they relate to solutions in one area being applied to another in gadget terms, applying function A, that makes gadget X so good, to gadget $\mathrm{Y}$. That this reflects the kind of thinking that might be described as ordinary or every day, rather than exceptional, is confirmed in the psychology 
literature where we see comments, such as 'analogy and similarity, are central in cognitive processing' (Gentner and Markman, 1997, p. 45). Indeed, this type of reasoning is widely recognised as a skill that we all employ from an early age (Siegler, 2000).

The second most popular choice $(23 \%)$ was that the idea resulted from what someone else in the group had said, which reflects the significance of interaction and is - again - indicative of something we all do every day, rather than something extraordinary. The remaining categories are all significantly smaller by comparison. One might expect that logical problem-solving (10\%) might score higher, but in this context, most of the time students are constructing a problem rather than solving one (Getzels, 1987). To take this into account, the category of Alertness (10\%) was also used, although this relates more to a general open state of mind, as discussed in Clark (2009), rather than a way of thinking per se. The hypothesis that the idea was a bolt from the blue, and therefore something of a mystery to the thinker, was supported in only one case, and the fact that, in general, the students were content to use the categories provided, suggests that the categories resonate in large degree. The exception in the sample relates to a case where the student could not identify the thinking as it resulted from an exercise in which students were forced to devise a product using random words without time to think, which seems to make it difficult to reflect on quite how the thoughts emerged. Nevertheless, although this could be seen as a bolt from the blue, it is the source of it that is semi-random, while the thinking rests on the interpretation of words and the degree to which words conjure up images, though magical they may be, cannot be considered exceptional.

\section{CONCLUSION}

While it cannot be denied that there is regional specialisation within the human brain, the results of this survey suggest that the current failure to find the 'part' that gives rise to creativity and invention should not be taken as evidence in support of the widespread notion that such a 'part' is intrinsically harder for the consciousness to access than other 'parts'. The author is undoubtedly biased, having come to the view that inventive thinking cannot be as mysterious, as generally supposed, since it can be effectively taught (Clark, 2009); and concluding from this, that its rarity has probably more to do with states of the world, and the constraints they impose, than states of mind and their rarity. Despite this bias, the author, nonetheless, contends that the research presented here provides an element of independent support for that view. This is not to suggest that inventive though is not mysterious, but only in the sense of Perkins (1981) who reminds us that all thinking is deeply mysterious and that to view everyday thinking as anything less is to skew the debate in favour of some form of dichotomy.

There are three broad pedagogic conclusions that come from this research. One is that the need for transcendence is removed, which may lead to a wider engagement with the teaching of invention and other creative pursuits within Business Schools and elsewhere. The second is that more students may feel able to engage in such activities, even if they have not previously labelled themselves as the 'creative type', if some of the mystery is removed. The final implication is that although there is a tension between the poorly-defined problems of invention and the emphasis in most educational programmes on well-defined ones, this does not mean that teaching invention necessarily entails engaging students in types of thinking that are alien to them because, although "ill-defined problems are ill understood by psychologists" (Pretz, et al., 2003, p.13), students are able to rise to the challenge as "most of the problems in the real world are not well defined". (ibid)

\section{AUTHOR INFORMATION}

Andre Clark is based at the University of Glamorgan in Wales. He has authored a number of textbooks and academic papers in the field of economics, business, and education. He is currently Chairman of Beacons Creative (Wales), a social enterprise, and is a trustee of the National Childbirth Trust, The UK's largest parenting charity. E-mail: Aclark1@glam.ac.uk 


\section{REFERENCES}

1. Allen, R. C. (1983), Collective invention, Journal of Economic Behavior and Organization, 4, 1-24.

2. $\quad$ Baer, M., Leenders, R. T. A. J., Oldham, G. R., and Vadera, A. K. (2010), Win or lose the battle for creativity: The power and perils of intergroup competition, Academy of Management Journal, 53 (4), 827 845.

3. Bijker, W. E. (1987), The Social Construction of Bakelite: Toward a Theory of Invention. p. 159-187 in The Social Construction of Technological Systems, edited by W. E. Bijker, T. P. Hughes, and T Pinch. Cambridge, MA: MIT Press.

4. $\quad$ Bush, V. (1945), As we may think, Atlantic monthly, 176 (1), 101-108.

5. Chavez-Eakle, R.A., Graff-Guerrero, A., Garcia-Reyna, J.C., Vaugier, V., and Cruz-Fuentes, C. (2007), Cerebral blood flow associated with creative performance: a comparative study, Neuroimage, 38, 519-28.

6. Churcher, P. A. (2010) Brain shape shows political allegiance, in The Independent Newspaper. $28^{\text {th }}$ Dec. London

7. Clark, A. (2009), An experiment in teaching invention, Education + Training, 51 (7), 516-525.

8. Diehl, M., and Stroebe, W. (1987), Productivity loss in brainstorming groups: Toward the solution of a riddle, Journal of Personality and Social Psychology, 53 (3), 497-509.

9. Duch W. (2007), Creativity and the Brain, in A Handbook of Creativity for Teachers, Ed. Ai-Girl Tan, Singapore: World Scientific Publishing 2007, 507-530.

10. Fink, A., Benedek, M., Grabner, R.H., Staudt, B., and Neubauer, A.C. (2007), Creativity meets neuroscience: Experimental tasks for the neuroscientific study of creative thinking, Methods, 42 (1), 68-76.

11. Fink, A., Grabner R.H., Benedek, M., Reishofer, G., Hauswirth, V., Fally, M., Neuper. C., Ebner, F., and Neubauer, A.C. (2009), The creative brain: Investigation of brain activity during creative problem solving by means of EEG and FMRI, Human Brain Mapping, 30 (3), 734-748.

12. Finke, R., Ward, T.B., and Smith, S.M. (1992), Creative cognition: Theory, research, and applications. MIT Press.

13. Geake, J.G., and Hansen, P.C. (2005), Neural correlates of intelligence as revealed by fMRI of fluid analogies, Neuroimage, 26, 555-564.

14. Gentner, D., and Markman, A.B. (1997) Structure mapping in analogy and similarity, American Psychologist, 52 (1), 45-56.

15. Getzels, J.W. (1987), Creativity, intelligence, and problem finding: retrospect and prospect, in Isaksen, S.C. (ed.) Frontiers of creativity research. Buffalo: Bearly, 88-102.

16. Heilman, K.M., Nadeau S.E., and Beversdorf, D.O. (2003), Creative innovation: possible brain mechanisms, Neurocase, 9 (5), 369-79.

17. Hendry, D.F., and Richard, J-F. (1989), Recent developments in the theory of encompassing, Ch. 12 in B. Cornet, and H. Tulkens (eds), Contributions to Operations Research and Economics: The twentieth anniversary of CORE, Cambridge, Mass. MIT Press, 393-440.

18. Hines, T. (1987). Left Brain/Right Brain Mythology and Implications for Management and Training, The Academy of Management Review, 12 (4), 600-606.

19. Hughes, T. P. (1983), Networks of Power: Electrification in Western Society, 1880-1930. Baltimore, Johns Hopkins University Press.

20. Koestler, A. (1975), The Act of Creation, Pan Books, London.

21. Kurtzberg, T. R. (2000), Creative styles and teamwork: Effects of coordination and conflict on group outcomes. Unpublished doctoral dissertation. Northwestern University, Evanston.

22. Meneely, J., and Portillo, M. (2005), The adaptable mind in design: Relating personality, cognitive style, and creative performance, Creativity Research Journal, 17 (2), 155-166.

23. Meyer, P. B. (2003), Episodes of collective invention, US Bureau of Labor Statistics Working Paper, No. 368.

24. Morgan, D.N. (1953), Creativity today: A constructive analytic review of certain philosophical and psychological work", Journal of Aesthetics and Art Criticism, 12 (1), 1-24.

25. Osborn, A. F. (1957), Applied Imagination; Principles and Procedures of Creative Thinking 2nd ed. Scribner, New York.

26. Perkins, D.N. (1981), The Mind's Best Work, Harvard University Press, Cambridge, MA. 
27. Pretz, J.E., Naples, A. J. and Sternberg, R. J. (2003), Recognizing, defining, and representing problems, in Davidson, J. E. and Sternberg, R. J. (Eds), The Psychology of Problem Solving, Cambridge University Press. Cambridge, 3-31.

28. Scranton, P. (1977), Endless Novelty: Specialty Production and American Industrialization, 1865-1925, Princeton University Press. Princeton, NJ.

29. Siegler, R. S. (2000), The rebirth of children's learning, Child Development, 71, 26-35.

30. Sternberg, R. J. (1985), Beyond IQ, Cambridge University Press. New York.

31. Sternberg, R. J., and Lubart, T. I. (1995), Defying the crowd: Cultivating creativity in a culture of conformity, Free Press. New York.

32. Taylor, D.W., Berry, P.C., and Block, C.H. (1958), Does group participation when using brainstorming facilitate or inhibit creative thinking? Administrative Science Quarterly, 3 (1), 23-47

33. Weisberg, R.W. (1993), Creativity: Beyond the myth of genius, W. H. Freeman. New York. 


\section{APPENDIX}

\section{PART 1 OF QUESTIONS}

\section{Student number:}

For the following statements, please put a tick in the box that best reflects what you feel:

1. I am a creative type of person.

\begin{tabular}{|l|l|l|l|}
\hline $\begin{array}{l}3 \% \\
\text { Strongly } \\
\text { Disagree }\end{array}$ & $\begin{array}{l}30 \% \\
\text { Somewhat } \\
\text { Disagree }\end{array}$ & $\begin{array}{l}40 \% \\
\text { Somewhat } \\
\text { Agree }\end{array}$ & $\begin{array}{l}27 \% \\
\text { Strongly Agree }\end{array}$ \\
\hline
\end{tabular}

2. I wanted to do well in this 'invention' task.

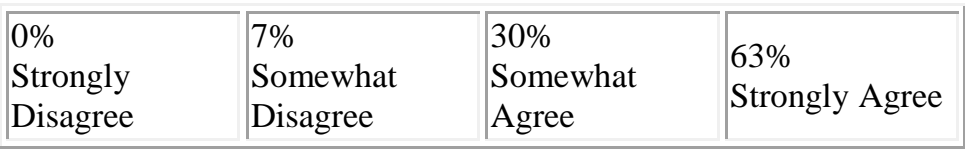

3. The group brought out my creativity.

\begin{tabular}{|l|l|l|l|}
\hline $11 \%$ & $2 \%$ & $39 \%$ & \\
$\begin{array}{l}\text { Strongly } \\
\text { Disagree }\end{array}$ & $\begin{array}{l}\text { Somewhat } \\
\text { Disagree }\end{array}$ & $\begin{array}{l}\text { Somewhat } \\
\text { Agree }\end{array}$ & $\begin{array}{l}48 \% \\
\text { Strongly Agree }\end{array}$ \\
\hline
\end{tabular}

4. I enjoyed this task.

\begin{tabular}{|l|l|l|l|}
\hline $\begin{array}{l}0 \% \\
\text { Strongly } \\
\text { Disagree }\end{array}$ & $\begin{array}{l}20 \% \\
\text { Somewhat } \\
\text { Disagree }\end{array}$ & $\begin{array}{l}10 \% \\
\text { Somewhat } \\
\text { Agree }\end{array}$ & $\begin{array}{l}70 \% \\
\text { Strongly Agree }\end{array}$ \\
\hline
\end{tabular}

5. I wanted to beat the others in this task.

\begin{tabular}{|l|l|l|l|}
\hline $\begin{array}{l}0 \% \\
\begin{array}{l}\text { Strongly } \\
\text { Disagree }\end{array}\end{array}$ & $\begin{array}{l}20 \% \\
\text { Somewhat } \\
\text { Disagree }\end{array}$ & $\begin{array}{l}57 \% \\
\text { Somewhat } \\
\text { Agree }\end{array}$ & $\begin{array}{l}23 \% \\
\text { Strongly Agree }\end{array}$ \\
\hline
\end{tabular}

6. Men are the best at invention because men think differently.

\begin{tabular}{|l|l|l|l|}
\hline $\begin{array}{l}10 \% \\
\begin{array}{l}\text { Strongly } \\
\text { Disagree }\end{array}\end{array}$ & $\begin{array}{l}20 \% \\
\text { Somewhat } \\
\text { Disagree }\end{array}$ & $\begin{array}{l}20 \% \\
\text { Somewhat } \\
\text { Agree }\end{array}$ & $\begin{array}{l}50 \% \\
\text { Strongly Agree }\end{array}$ \\
\hline
\end{tabular}

7. Coming up with strange ideas is a necessary part of the inventive process.

\begin{tabular}{|c|c|c|c|}
\hline \begin{tabular}{|l|}
$40 \%$ \\
Strongly \\
Disagree
\end{tabular} & $\begin{array}{l}20 \% \\
\text { Somewhat } \\
\text { Disagree }\end{array}$ & $\begin{array}{l}20 \% \\
\text { Somewhat } \\
\text { Agree }\end{array}$ & $\begin{array}{l}20 \% \\
\text { Strongly Agree }\end{array}$ \\
\hline
\end{tabular}

8. Please state which class you are in:

9. Please state whether you are male or female: (53\% male) 
Please do not fill in this form if you are unhappy with the terms of use. Please briefly describe the idea:

\section{PART 2 OF QUESTIONS}

Please tick which of the following best describes your thought process that led to your excellent idea.

1. Lateral, or counterfactual, thinking (3\%)

2. Analogous reasoning (47\%)

3. Bolt out of the blue (3\%)

4. Logical problem-solving (10\%)

5. An idea that someone else had in the group made me think of it (23\%)

6. Alertness $(10 \%)$

7. Other (please explain in the space provided) $(3 \%)$ 
NOTES 